\title{
Analisis Kualitas Layanan Website BPJS Kesehatan Dengan Menggunakan Metode Webqual 4.0
}

Analysis of BPJS Health Website Service Quality Using The Webqual 4.0 Method

\author{
Lisa Amelia \\ Sistem Informasi, STMIK GI MDP \\ E-mail: lisa@mdp.ac.id
}

\begin{abstract}
Abstrak
BPJS Kesehatan merupakan salah satu layanan kesehatan yang diberikan oleh pemerintah dalam memberikan perlindungan kesehatan kepada masyarakatnya. Website BPJS Kesehatan merupakan sarana yang digunakan oleh BPJS Kesehatan dalam memberikan informasi komunikasi dan publikasi kepada masyarakat. Untuk mengetahui kualitas layanan website yang diberikan apakah telah memberikan kepuasan kepada pengguna maka dilakukan penelitian terhadap kualitas layanan website BPJS Kesehatan. Metode webqual 4.0 digunakan dalam penelitian ini dengan menyebarkan kuesioner kepada pengguna dan kemudian menganalisis hasil dari kuesioner tersebut. Hasil yang diperoleh menunjukkan kualitas layanan website BPJS Kesehatan dengan variabel penelitian kualitas kegunaan dan kualitas interaksi layanan mempengaruhi kepuasan pengguna secara parsial namun variabel kualitas informasi tidak mempengaruhi kepuasan pengguna secara parsial.
\end{abstract}

Kata kunci: BPJS Kesehatan, Website, Webqual 4.0

\begin{abstract}
BPJS Kesehatan is one of the health services provided by the government in providing health protection to its people. The BPJS Health website is a means used by BPJS Kesehatan in providing communication information and publications to the public. To find out the quality of the website services provided, whether it has satisfied users, a research was conducted on the quality of the BPJS Health website service. The webqual 4.0 method was used in this study by distributing questionnaires to users and then analyzing the results of the questionnaire. The results obtained indicate the quality of the BPJS Kesehatan website service with the research variables of usability quality and service interaction quality partially affecting user satisfaction, but the information quality variable does not partially affect user satisfaction.
\end{abstract}

Keywords: BPJS Kesehatan, Website, Webqual 4.0

\section{PENDAHULUAN}

Sejak zaman kolonial Belanda jaminan kesehatan di negara Indonesia telah ada. Menteri Kesehatan yang menjabat pada saat itu, Prof. G.A. Siwabessy mengajukan sebuah gagasan untuk menyelenggarakan program asuransi kesehatan semesta (universal health insurance) yang saat itu mulai diterapkan di banyak negara maju dan tengah berkembang pesat. Seiring berjalannya program jaminan kesehatan sampai saat ini pemerintah mendirikan Badan Penyelenggara Jaminan Sosial (BPJS) Kesehatan yang merupakan transformasi dari PT. Askes (Persero) yang ditujukan bagi masyarakat yang belum tercover oleh Jamkesmas, Askes Sosial, maupun asuransi swasta.

Program yang digalang oleh BPJS Kesehatan didirikan untuk memastikan seluruh penduduk Indonesia terlindungi oleh jaminan kesehatan yang komprehensif, adil, dan merata. 
Dengan berbagai layanan dan manfaat yang diberikan, BPJS Kesehatan berharap seluruh masyarakat Indonesia mendapatkan pelayanan kesehatan yang maksimal. Dikarenakan tanggung jawab tersebut, BPJS Kesehatan-pun terus berupaya meningkatkan seluruh lini pelayanan sambil terus mengembangkan berbagai program dan manfaat yang dapat digunakan oleh masyarakat yang membutuhkan. Salah satunya dengan memberikan pelayanan website BPJS Kesehatan (https://bpjs-kesehatan.go.id).

Melalui website BPJS Kesehatan, masyarakat dapat mengetahui manfaat yang diperoleh peserta, besaran iuran, prosedur pendaftaran, layanan publik, panduan layanan serta informasiinformasi lainnya yang tersedia pada website BPJS Kesehatan. Namun dari layanan website yang telah diberikan masih mendapat pertanyaan dari peserta BPJS bahwa dalam penerapannya kualitas website BPJS Kesehatan masih mendapatkan keluhan dari pengguna. Oleh sebab itu peneliti berupaya mencari tahu mengenai kualitas dari website BPJS Kesehatan menurut tanggapan pengguna.

\section{METODE PENELITIAN}

Untuk pengukuran kualitas website pada penelitian ini, peneliti menggunakan metode deskriptif kuantitatif. Instrumen yang digunakan dalam penelitian ini adalah dengan cara penyebaran kuesioner kepada masyarakat yang telah menggunakan layanan website BPJS Kesehatan. Studi literatur dilakukan untuk menemukan teori-teori yang berkaitan dengan permasalahan sehingga dapat di tentukan variabel-variabel penelitiannya.

Setelah variabel penelitian di tentukan maka tahap selanjutnya adalah menyusun kuesioner yang akan di sebarkan pada populasi atau sampel yang memenuhi syarat untuk mengisi kuesioner. Hasil kuesioner yang terkumpul kemudian akan di analisis dengan melakukan uji validitas dan reliabilitas untuk mengetahui apakah data yang diperoleh layak untuk dihitung. Apabila data yang diperoleh telah valid dan reliabel maka kemudian akan dilakukan uji asumsi klasik dan analisis regresi kemudian hasil analisis yang diperoleh diinterpretasikan sehingga dapat diketahui rekomendasi apa yang dapat diberikan untuk permasalahan yang ada. Terakhir akan dibuat simpulan dan saran atas penelitian ini.

\section{$2.1 \quad$ Kuesioner}

Pada penelitian ini data diperoleh dengan cara penyebaran kuesioner. Menurut [1] kuesioner adalah daftar pertanyaan yang diberikan kepada orang lain yang bersedia memberikan respon sesuai dengan permintaan pengguna. Penulis menggunakan teknik pengumpulan data dengan penyebaran kuesioner karena teknik ini dianggap efisien dan penulis dapat memastikan ukuran variabel yang ingin di teliti. Kuesioner merupakan daftar pernyataan tertulis yang telah dirancang sebelumnya dan akan disebarkan ke responden untuk dijawab. Kuesioner yang dibagikan kepada responden berisikan pernyataan-pernyataan, kemudian akan diukur dengan menggunakan skala likert dengan penilaian antara sangat puas sampai sangat tidak puas terhadap pernyataan yang telah diberikan.

Tabel 1. Pernyataan Kuesioner

\begin{tabular}{|c|l|c|}
\hline Variabel & \multicolumn{1}{|c|}{ Pertanyaan Kuesioner } & \\
\hline \multirow{5}{*}{ Kualitas Kegunaan } & Website BPJS Kesehatan mudah dipelajari & X11 \\
\cline { 2 - 3 } & Website BPJS Kesehatan mudah dioperasikan & X12 \\
\cline { 2 - 3 } & Website BPJS Kesehatan memiliki tampilan yang menarik & X13 \\
\cline { 2 - 3 } & Website BPJS Kesehatan memiliki desain yang sesuai & X14 \\
\cline { 2 - 3 } & Website BPJS Kesehatan tampak meyakinkan dan kompeten & X15 \\
\cline { 2 - 3 } & $\begin{array}{l}\text { Website BPJS Kesehatan memberikan pengalaman yang positif } \\
\text { bagi pengguna }\end{array}$ & X16 \\
\hline Kualitas Informasi & Informasi yang disediakan pada Website BPJS Kesehatan akurat & X21 \\
\hline
\end{tabular}




\begin{tabular}{|l|l|c|}
\hline \multirow{5}{*}{} & $\begin{array}{l}\text { Informasi yang disediakan pada Website BPJS Kesehatan dapat } \\
\text { dipercaya }\end{array}$ & $\mathrm{X} 22$ \\
\cline { 2 - 3 } & $\begin{array}{l}\text { Informasi yang disediakan pada Website BPJS Kesehatan tepat } \\
\text { waktu }\end{array}$ & $\mathrm{X} 23$ \\
\cline { 2 - 3 } & Informasi yang disediakan pada Website BPJS Kesehatan relevan & $\mathrm{X} 24$ \\
\cline { 2 - 3 } & $\begin{array}{l}\text { Informasi yang disediakan pada Website BPJS Kesehatan mudah } \\
\text { dimengerti }\end{array}$ & $\mathrm{X} 25$ \\
\cline { 2 - 3 } & $\begin{array}{l}\text { Informasi yang disediakan pada Website BPJS Kesehatan disajikan } \\
\text { secara detail yang tepat }\end{array}$ & $\mathrm{X} 26$ \\
\cline { 2 - 3 } & $\begin{array}{l}\text { Informasi yang disediakan pada Website BPJS Kesehatan dalam } \\
\text { format yang sesuai }\end{array}$ & $\mathrm{X} 27$ \\
\hline \multirow{5}{*}{ Kualitas Interaksi } & Website BPSS Kesehatan memiliki reputasi yang baik & $\mathrm{X} 31$ \\
\cline { 2 - 3 } & $\begin{array}{l}\text { Website BPJS Kesehatan memberikan rasa aman terhadap } \\
\text { informasi data pribadi pengguna }\end{array}$ & $\mathrm{X} 32$ \\
\cline { 2 - 3 } $\begin{array}{l}\text { Website BPJS Kesehatan menciptakan rasa personalisasi atau } \\
\text { terjaminnya privasi pengguna }\end{array}$ & $\mathrm{X} 33$ \\
\cline { 2 - 3 } Pepuasan & Website BPJS Kesehatan memberikan ruang untuk komunitas & $\mathrm{X} 34$ \\
\cline { 2 - 3 } & $\begin{array}{l}\text { Website BPJS Kesehatan memberikan kemudahan pengguna untuk } \\
\text { berkomunikasi dengan organisasi }\end{array}$ & $\mathrm{X} 35$ \\
\hline & Informasi yang diberikan akurat & $\mathrm{Y} 1$ \\
\cline { 2 - 3 } & Website BPJS Kesehatan memberikan informasi tepat waktu & $\mathrm{Y} 1$ \\
\cline { 2 - 3 } & Website BPJS Kesehatan memberikan informasi terbaru & $\mathrm{Y} 1$ \\
\cline { 2 - 3 } & Output tampilan disajikan dalam format yang sesuai & $\mathrm{Y} 1$ \\
\cline { 2 - 3 } & $\begin{array}{l}\text { Website BPJS Kesehatan memberikan informasi yang sesuai } \\
\text { dengan kebutuhan Anda }\end{array}$ & $\begin{array}{l}\text { Website BPJS Kesehatan mudah di akses pada gadget atau media } \\
\text { lain }\end{array}$ \\
\hline
\end{tabular}

\subsection{Populasi}

Populasi merupakan kumpulan dari keseluruhan obyek yang akan diukur dalam penelitian [2]. Populasi dalam penelitian ini adalah seluruh pengguna website BPJS Kesehatan.

\subsection{Sampel}

Umar Sekaran [3] mendefinisikan sampel sebagai sub kelompok atau sebagian dari populasi, dimana sampel terdiri atas sejumlah anggota yang dipilih dari populasi. Pada penelitian ini sampelnya adalah pengguna website BPJS Kesehatan sebanyak 50 orang. Teknik yang digunakan dalam penelitian ini adalah teknik non probability sampling dengan metode sampling incidental. Menurut [4] "sampling incidental adalah dimana teknik penentuan sampel berdasarkan kebetulan, yaitu dengan siapa saja yang secara kebetulan atau incidental bertemu dengan peneliti dapat digunakan sebagai sampel".

\subsection{Webqual (Website Quality)}

Pada masa kini salah satu bentuk media komunikasi dan publikasi yang banyak digunakan adalah website. Teknologi pada website yang mudah digunakan, efisien dan jangkauan yang luas menjadikan website banyak di manfaatkan sebagai media komunikasi dan publikasi bagi banyak organisasi. Penyedia layanan website perlu memperhatikan kepuasan dari para menggunanya dimana kepuasan pengguna akan menjadi tolak ukur dari kualitas suatu website. Metode WebQual saat ini merupakan salah satu metode yang cukup banyak digunakan pada pengukuran kualitas website berdasarkan persepsi pengguna atau pengunjung [5].

Metode WebQual merupakan metode yang mengalami pengembangan dari metode mengukuran kualitas jasa yang banyak digunakan pada penelitian sebelumnya yaitu metode ServQual yang dirancang oleh Parasuraman [6]. Pada penelitian ini versi terbaru dari WebQual yaitu WebQual 4.0 akan digunakan dengan menggunakan tiga kategori pengukuran dengan 24 butir pertanyaan. Adapun tiga kategori yang digunakan untuk pengukurannya adalah Kualitas 
Kegunaan, Kualitas Informasi dan Kualitas Interaksi Layanan. Kategori Kualitas Kegunaan didasarkan pada kualitas yang dihubungkan dengan kemudahan penggunaan dan rancangan website, seperti tampilan website, website yang meyakinkan dan memberikan pengalaman yang positif kepada pengguna. Kategori Kualitas Informasi lebih menekankan pada kualitas informasi yang diberikan kepada pengguna misalnya dari isi informasi, dapat dipercaya, keakuratan, tepat waktu, relevan, kesesuaian format dan mudah dimengerti. Kategori Kualitas Interaksi Layanan berhubungan dengan reputasi, keamanan informasi pribadi, personalisasi, komunitas dan kemudahan berkomunikasi.

Tabel 2. Variabel Dalam Penelitian Webqual 4.0.

\begin{tabular}{|c|l|}
\hline Variabel & \multicolumn{1}{|c|}{ Keterangan } \\
\hline $\mathrm{X} 1$ & Kualitas Kegunaan \\
\hline $\mathrm{X} 2$ & Kualitas Informasi \\
\hline $\mathrm{X} 3$ & Kualitas Interaksi Layanan \\
\hline $\mathrm{Y}$ & Kepuasan Pengguna \\
\hline
\end{tabular}

\subsection{Uji Validitas}

Menurut [7], validitas menunjukkan ketepatan dan kecermatan alat ukur dalam melakukan fungsi ukurnya. Dalam penelitian ini uji validitas digunakan untuk melihat apakah penyataan-pertanyaan pada kuesioner yang sebarkan kepada repsonden valid atau tidak. Pengambilan keputusan dalam penelitian ini dengan menggunakan kriteria perbandingan nilai $r_{\text {hitung }}$ dan $r_{\text {tabel }}$. Apabila nilai $r_{\text {hitung }}<$ nilai $r_{\text {tabel }}$ maka penyataan kuesioner yang digunakan dalam penelitian ini dinyatakan tidak valid, namun apabila nilai $r_{\text {hitung }}>r_{\text {tabel }}$ maka pernyataan kuesioner yang digunakan dalam penelitian ini dinyatakan valid.

\subsection{Uji Reliabilitas}

Uji Reliabilitas pada penelitian ini digunakan untuk menguji keandalan alat ukur pengumpulan data dan memastikan apakah penyataan yang digunakan dalam penelitian ini dapat dipercaya sebagai alat pengumpulan data. Suatu alat ukur dikatakan andal apabila menunjukkan tingkat ketepatan, keakuratan, kestabilan atau konsistensi alat tersebut dalam mengungkapkan gejala tertentu dari sekelompok individual, walaupun dilakukan pada waktu yang berbeda. Adapun kriteria pengambilan keputusan dalam penelitian ini dilihat dengan menggunakan nilai Cronbach"s Alpha. Item dikatakan reliabel jika nilai Cronbach's Alpha lebih besar dari nilai kritis. Nilai kritis yang ditetapkan adalah antara 0,6 dan 0,7 [8].

\subsection{Uji Asumsi Klasik}

Agar hasil model regresi yang diperoleh tidak bias maka dilakukan uji asumsi klasik yang meliputi uji Normalitas, Multikolinearitas dan Heteroskedastisitas.

\subsection{Perancangan Konstruk}

Konstruk adalah elemen dari kuesioner yang digunakan untuk mendefinisikan tujuan penilaian sebuah kuesioner terhadap objek kuesioner. Konstruk untuk penelitian ini ditunjukkan pada gambar berikut: 


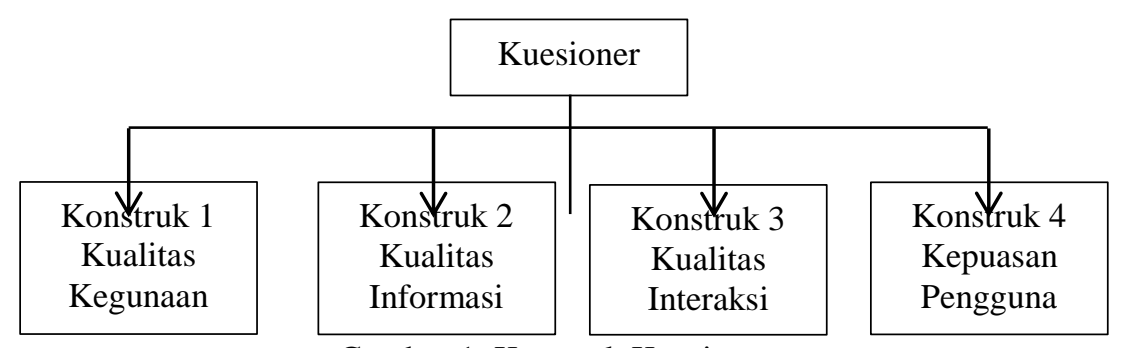

Gambar 1. Konstruk Kuesioner

\subsection{Pengukuran Variabel}

Untuk pengukuran variabel penelitian digunakan skala Likert dengan penjelasan sbb:

1. Kuesioner yang telah di rancang di sebarkan kepada responden.

2. Responden diminta untuk menjawab pertanyaan - pertanyaan yang diberikan dengan memilih penilaian $1-5$ atas dasar persepsi masing - masing responden. Jawaban terdiri dari lima pilihan, yakni: Sangat puas, Puas, Cukup, Tidak puas, dan Sangat tidak puas.

3. Pembobotan nilai yang diberikan untuk jawaban Sangat puas adalah nilai 5, dan seterusnya menurun sampai pada jawaban Sangat tidak puas yang diberikan nilai 1.

Tabel 3. Bobot Nilai Jawaban Responden

\begin{tabular}{|c|c|}
\hline Jawaban & Nilai \\
\hline Sangat puas & 5 \\
\hline Puas & 4 \\
\hline Cukup & 3 \\
\hline Tidak puas & 2 \\
\hline Sangat tidak puas & 1 \\
\hline
\end{tabular}

\section{HASIL DAN PEMBAHASAN}

\subsection{Uji Validitas}

Untuk mengetahui bahwa suatu kuesioner sah atau valid digunakan sebagai alat ukur maka dilakukan uji validitas terlebih dahulu. Uji validitas dilakukan dengan membandingkan antara nilai $r_{\text {hitung }}$ dengan nilai $r_{\text {tabel }}$. Apabila $r_{\text {hitung }}>$ dari $r_{\text {tabel }}$ maka suatu pengujian validitas dapat dikatakan valid, namun apabila nilai $r_{\text {hitung }}<$ dari $r_{\text {tabel }}$ maka dapat dikatakan tidak valid. Dengan signifikansi 0,05 maka di dapat $r_{\text {tabel }}$ sebesar 0,2787. Berikut hasil uji validitas yang diperoleh :

Tabel 4. Hasil Uji Validitas Kuisioner

\begin{tabular}{|c|c|c|c|c|c|}
\hline No & $\begin{array}{c}\text { Kode } \\
\text { Kuisioner }\end{array}$ & $\begin{array}{c}\mathrm{r} \\
\text { hitung }\end{array}$ & No & $\begin{array}{c}\text { Kuisioner } \\
\text { Kode }\end{array}$ & $\begin{array}{c}\mathrm{r} \\
\text { hitung }\end{array}$ \\
\hline 1 & $\mathrm{X} 1_{1}$ & 0,495 & 18 & $\mathrm{X} 27$ & 0,606 \\
\hline 2 & $\mathrm{X} 1_{2}$ & 0,511 & 19 & $\mathrm{X} 31_{1}$ & 0,575 \\
\hline 3 & $\mathrm{X} 13$ & 0,589 & 20 & $\mathrm{X} 3{ }_{2}$ & 0,537 \\
\hline 4 & $\mathrm{X} 1_{4}$ & 0,402 & 21 & $\mathrm{X} 33$ & 0,602 \\
\hline 5 & $\mathrm{X} 15$ & 0,496 & 22 & $\mathrm{X} 34$ & 0,661 \\
\hline 6 & $\mathrm{X} 16$ & 0,536 & 23 & $\mathrm{X} 35$ & 0,630 \\
\hline 7 & $\mathrm{X} 2{ }_{1}$ & 0,620 & 24 & $\mathrm{Y}_{1}$ & 0,598 \\
\hline 8 & $\mathrm{X} 2{ }_{2}$ & 0,706 & 25 & $\mathrm{Y}_{2}$ & 0,608 \\
\hline 9 & $\mathrm{X} 2{ }_{3}$ & 0,458 & 26 & $\mathrm{Y}_{3}$ & 0,590 \\
\hline
\end{tabular}




\begin{tabular}{|l|l|l|l|l|l|}
10 & $\mathrm{X}_{4}$ & 0,725 & 27 & $\mathrm{Y}_{4}$ & 0,556 \\
\hline 11 & $\mathrm{X} 25$ & 0,695 & 28 & $\mathrm{Y}_{5}$ & 0,527 \\
\hline 12 & $\mathrm{X} 26$ & 0,573 & 29 & $\mathrm{Y}_{6}$ & 0,636 \\
\hline
\end{tabular}

Dari hasil uji validitas yang diperoleh pada tabel 4 di atas, maka diperoleh hasil $\mathbf{r}_{\text {hitung }}>$ $\mathrm{r}_{\text {tabel }}$ yang berarti kuesioner yang digunakan sebagai alat ukur dalam penelitian ini dinyatakan valid.

\subsection{Uji Reliabilitas}

Setelah uji validitas dilakukan maka selanjutnya kan dilakukan uji reliabilitas. Metode Cronbach Alpa di gunakan untuk melakukan pengujian dalam penelirian ini. Apabila nilai Cronbach Alpa yang diperoleh > 0,6 maka dapat disimpulkan bahwa kuesioner tersebut reliabel tetapi sebaliknya jika nilai Cronbach Alpa < 0,6 maka dapat disimpulkan kuesioner yang digunakan dalam penelitian ini tidak reliabel. Hasil pengujian reliabilitas dalam penelitian ini sebagai berikut :

Tabel 5. Hasil Uji Reliabilitas Kuesioner
\begin{tabular}{|c|c|}
\hline Variabel & Cronbach's Alpha \\
\hline X1 & 0,843 \\
\hline X2 & 0,871 \\
\hline X3 & 0,865 \\
\hline Y & 0,887 \\
\hline
\end{tabular}

Dari hasil pengujian pada tabel di atas, dapat dilihat dari keempat variabel nilai Cronbach's Alpha yang menunjukkan > dari 0,6, maka dapat dinyatakan bahwa keempat variabel reliabel.

\subsection{Uji Normalitas}

Untuk mengetahui sebaran data pada variabel apakah berdistribusi normal atau tidak maka dilakukan uji normalitas. Dasar pengambilan keputusan dari pengujian ini apabila tingkat signifikansi lebih besar dari 0,05 maka distribusi data dinyatakan memenuhi asumsi normalitas tetapi apabila nilai signifikansi lebih kecil dari 0,05 maka data dinyatakan berdistribusi tidak normal.

Tabel 6. Hasil Uji Normalitas

One-Sample Kolmogorov-Smirnov Test

\begin{tabular}{|ll|r|}
\hline & & $\begin{array}{c}\text { Unstandardized } \\
\text { Residual }\end{array}$ \\
\hline Normal Parameters ${ }^{\mathrm{a}}$ & Mean & 50 \\
& Std. Deviation & 0,0000000 \\
Most Extreme Differences & Absolute & 1,15010175 \\
& Positive & 0,144 \\
& Negative & 0,123 \\
Kolmogorov-Smirnov Z & & $-0,144$ \\
Asymp. Sig. (2-tailed) & & 1,020 \\
\end{tabular}

Dari hasil tabel 6 di atas, dapat dilihat bahwa nilai signifikansi > 0,05 yaitu 0.249, maka pengujian menunjukkan bahwa sebaran data terdistribusi normal. 


\subsection{Uji Multikolinearitas}

Uji multikolinearitas bertujuan untuk menguji apakah antara variabel bebas yang digunakan dalam penelitian ini memiliki korelasi yang tinggi atau tidak. Dasar pengambilan keputusan pada uji multikolinearitas yang digunakan apabila nilai tolerance $>0.01$ dan VIF < 0,10 maka artinya variabel yang digunakan dalam penelitian ini tidak terjadi multikolinearitas. Sebaliknya apabila nilai tolerance $<0.01$ dan VIF $>10$ dapat disimpulkan bahwa variabel dalam penelitian ini terjadi multikolinearitas.

Tabel 7. Hasil Uji Multikolinearitas

\begin{tabular}{|l|c|c|}
\hline \multirow{2}{*}{\multicolumn{1}{|c|}{ Model }} & \multicolumn{2}{|c|}{ Collinearity Statistics } \\
\cline { 2 - 3 } & Tolerance & VIF \\
\hline Kualitas Kegunaan & 0,249 & 4,009 \\
\hline Kualitas Informasi & 0,349 & 8,869 \\
\hline Kualitas Interaksi & 0,406 & 2,465 \\
\hline
\end{tabular}

Dari tabel 7 di atas dapat dilihat bahwa nilai tolerance dan VIF > 0,10, maka dari hasil pengujian ini dapat disimpulkan tidak terjadi multikolinearitas dalam model regresi.

\subsection{Uji Hetereoskedastisitas}

Uji hetereoskedastisitas bertujuan untuk melihat bahwa dalam penelitian ini tidak terjadi kesamaan varians dari residual. Dasar pengambilan keputusan dikatakan tidak terjadi gejala Heteroskedastisitas apabila hasil grafik menunjukkan titik menyebar tidak beraturan di atas dan di bawah titik 0 pada sumbu y.

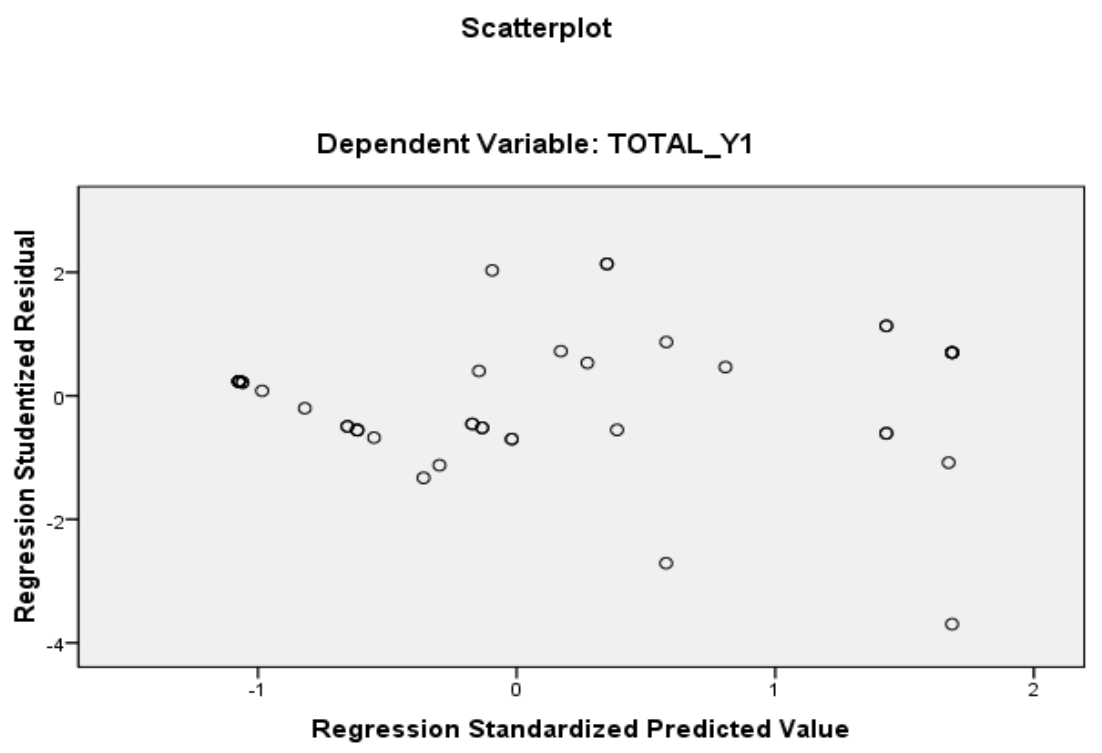

Gambar 2. Hasil Uji Heteroskedastisitas

Dari hasil pengujian yang tertera pada gambar 2 di atas, hasil uji heteroskedastisitas dengan grafik menunjukkan titik menyebar tidak beraturan di atas dan di bawah titik 0 pada sumbu y, maka dapat disimpulkan tidak terdapat gejala heteroskedastisitas.

\subsection{Analisis Pengaruh}

\subsubsection{Uji F}


Untuk mengetahui apakah variabel bebas berpengaruh terhadap variabel terikat secara bersama-sama maka akan dilakukan uji F. Kriteria pengambilan keputusan dengan menggunakan nilai tingkat signifikansi sebesar 0,05. Apabila tingkat signifikansi hasil uji < 0,05, dapat dikatakan bahwa variabel bebas berpengaruh terhadap variabel terikat secara bersama-sama. Tetapi apabila tingkat signifikansi hasil uji yang diperoleh $>0,05$ dikatakan bahwa variabel bebas tidak berpengaruh terhadap variabel terikat secara bersama-sama.

\begin{tabular}{|c|c|c|c|c|c|c|}
\hline \multicolumn{7}{|c|}{$\begin{array}{c}\text { Tabel 8. Hasil Uji F } \\
\text { ANOVA }^{\mathbf{a}}\end{array}$} \\
\hline & & Sum of Squares & df & Mean Square & $\mathrm{F}$ & Sig. \\
\hline \multirow[t]{3}{*}{1} & Regression & 193,206 & 3 & 64,402 & 45,708 & $0,000^{b}$ \\
\hline & Residual & 64,814 & 46 & 1,409 & & \\
\hline & Total & 258,020 & 49 & & & \\
\hline
\end{tabular}

a. Dependent Variable: TOTAL_Y1

b. Predictors: (Constant), TOTAL_X3, TOTAL_X2, TOTAL_X1

Tingkat signifikansi yang di peroleh dari hasil pengujian pada tabel 8 di atas sebesar $0,000<$ dari 0,05. Hal ini menunjukkan bahwa secara simultan, variabel Kualitas Kegunaan, Kualitas Informasi dan Kualitas Interaksi berpengaruh secara signifikan terhadap variabel kepuasan pengguna dalam hal penggunaan website di BPJS Kesehatan.

\subsubsection{Uji t}

Untuk mengetahui apakah variabel bebas berpengaruh secara parsial terhadap variabel terikat pada penelitian ini maka dilakukan uji t. Tingkat signifikansi yang dijadikan dasar pengambilan keputusan dalam penelitian ini adalah $<0,05$. Apabila tingkat signifikansi $<0,05$ maka dapat dikatakan bahwa antara variabel bebas terhadap variabel terikat berpengaruh secara parsial, tetapi apabila tingkat signifikansi yang diperoleh > 0,05, maka dapat dikatakan variabel bebas tidak berpengaruh secara signifikan terhadap variabel terikat.

\begin{tabular}{|c|c|c|c|c|c|c|}
\hline \multicolumn{7}{|c|}{$\begin{array}{l}\text { Tabel 9. Hasil Uji t } \\
\text { Coefficients }^{\mathbf{a}}\end{array}$} \\
\hline \multirow{2}{*}{\multicolumn{2}{|c|}{ Model }} & \multicolumn{2}{|c|}{ Unstandardized Coefficients } & \multirow{2}{*}{$\begin{array}{c}\begin{array}{c}\text { Standardized } \\
\text { Coefficients }\end{array} \\
\text { Beta } \\
\end{array}$} & \multirow[b]{2}{*}{$\mathrm{t}$} & \multirow[b]{2}{*}{ Sig. } \\
\hline & & B & Std. Error & & & \\
\hline \multirow[t]{4}{*}{1} & (Constant) & 1,304 & 1,619 & & 0,805 & 0,425 \\
\hline & TOTAL_X1 & 0,328 & 0,147 & 0,331 & 2,235 & 0,030 \\
\hline & TOTAL_X2 & 0,177 & 0,107 & 0,207 & 1,652 & 0,105 \\
\hline & TOTAL_X3 & 0,454 & 0,129 & 0,409 & 3,529 & 0,001 \\
\hline
\end{tabular}

a. Dependent Variable: TOTAL_Y1

Pada tabel 9 diatas, didapatkan nilai signifikansi dari setiap variabel Kualitas Kegunaan, Kualitas Informasi dan Kualitas Interaksi masing-masing sebesar : 0,030, 0,105 dan 0,001, hal ini menunjukkan dua variabel bebas Kualitas Kegunaan dan Kualitas Interaksi memiliki tingkat signifikansi $<0.05$, sehingga dapat disimpulkan bahwa kedua variabel tersebut berpengaruh terhadap kepuasan pengguna secara parsial. Namun pada variabel Kualitas Informasi nilai signifikansi yang diperoleh sebesar 0,105 > 0.05, sehingga menunjukkan bahwa variabel Kualitas Informasi tidak berpengaruh terhadap kepuasan pengguna secara parsial.

\section{KESIMPULAN DAN SARAN}

Berdasarkan hasil pengujian kualitas layanan website BPJS Kesehatan dengan menggunakan metode WebQual 4.0, maka dapat ditarik kesimpulan bahwa kualitas layanan website BPJS Kesehatan dengan variabel penelitian kualitas kegunaan dan kualitas interaksi 
mempengaruhi kepuasan pengguna secara parsial namun variabel kualitas informasi tidak mempengaruhi kepuasan pengguna secara parsial, sehingga dapat diberikan saran bagi pengelola website BPJS Kesehatan agar dapat lebih meningkatkan kualitas layanan website sehingga dapat memberikan layanan yang maksimal kepada pengguna dan diharapkan layanan website BPJS Kesehatan dapat terus di kembangkan lagi dan untuk penelitian berikutnya dapat di buat pertanyaan terbuka kepada responden agar dapat memperoleh masukkan atas layanan seperti apa yang di inginkan oleh pengguna website BPJS Kesehatan.

\section{DAFTAR PUSTAKA}

[1] Riduwan. 2005. Skala Pengukuran Variabel-variabel Penelitian. Alfabeta. Bandung.

[2] Cooper, Donald R. and Pemela S. Schindler. 2003. Business Research Methods, International Edition, McGraw-Hill Companies, Inc. New York.

[3] U. Sekaran, 2006, Research Methods for Business, Salemba Empat, Jakarta.

[4] Sugiyono. 2016. Metode Penelitian Kuantitatif Kualitatif dan R\&D. Alfabeta. Bandung.

[5] C. Irawan, 2012. "Evaluasi Kualitas Website Pemerintah Daerah Dengan Menggunakan WebQual (Studi Kasus Pada Kabupaten Ogan Ilir), ” Jurnal Sistem Informasi (JSI), Vol. 4, No. -, pp. 488-502

[6] D. B. Napitupulu, 2016. "Evaluasi Kualitas Website Universitas XYZ Dengan Pendekatan Webqual," Buletin Pos dan Telekomunikasi, Vol. 14, No.1, pp. 51-6.

[7] Sekaran, Uma. 2003. Research Methods for Business: Skill-Building Approach. fourth edition. John Wiley \& Sons Inc. New York.

[8] Sugiyono. 2003. Metode Penelitian. Alfabeta, Bandung. 